\title{
GOVERNO PLURAL DAS POLÍTICAS HABITACIONAIS. Interações com os processos recentes de reestruturação dos territórios populares da metrópole paulistana
}

\author{
PLURAL GOVERNMENT OF HOUSING POLICIES \\ Interactions with recent processes of reestructuring of popular \\ territories of the metropolitan region of São Paulo, Brazil
}

\author{
A. Camila Moreno de Camargo \\ Universidade de São Paulo, Brasil \\ cmcamargo@usp.br
}

\begin{abstract}
RESUMO
O presente artigo parte da urgência em se estabelecer um novo quadro de legibilidade sobre as condições da desigualdade urbana no Brasil atual e aponta o programa MCMV Entidades como lente ainda plausível para se compreender os nexos entre o atual regime de acumulação de capital e as transformações na reestruturação de territórios populares metropolitanos. Nesta direção, a partir dos contratos recentes do programa que se inserem em outro contexto político e social, o artigo aponta para o entrelaçamento e confluência entre programas habitacionais distintos, a partir de seus níveis de concepção, dos agenciamentos em torno de sua operacionalização e implementação no território, atuando como dispositivos de gestão da insegurança habitacional frente a um processo de reestruturação dos territórios populares da metrópole paulistana.
\end{abstract}

Palavras-chave: política habitacional, Região Metropolitana de São Paulo, MCMV Entidades, movimentos de moradia

Linha de Investigação: 1 . Cidade e projeto

Tópico: Estudos metropolitanos e territoriais

\section{ABSTRACT}

This research project starts from the urgency of establishing a new framework on the conditions of urban inequality in Brazil's current context, and points to the MCMV Entities housing program as a still plausible lens to understand the links between the current capital accumulation regime and the transformations in the restructuring process of metropolitan popular territories, that results in precarious and reconfigured forms of housing and insertion in the city. In this direction, from the recent contracts of the program that fall into another political and social context, the article points to the confluence between distinct housing programs, from their conception levels, the agencies around their operationalization and implementation in the territory, acting as housing insecurity management, in face of a restructuring process of the popular territories in the São Paulo metropolitan city. 


\section{XII}

Keywords: housing policy, Metropolitan Region of São Paulo, MCMV Entities, housing movements.

Research line: 1 . City and project.

Topic: Metropolitan and territorial studies.

\section{Novo quadro de legibilidade para os territórios populares}

Os nexos entre acumulação e pobreza foram evidenciados por Oliveira (1972) que apontou para um conjunto de práticas e processos econômicos, demográficos e urbanos, considerados arcaicos que, ao lado da regulamentação das relações de trabalho e de inúmeras intervenções na esfera econômica, cumpriram um papel fundamental para a implantação da base capitalista industrial no país. Dessa perspectiva, a produção de habitação pelos próprios trabalhadores, a chamada autoconstrução, bem como as dinâmicas de urbanização e suas peculiaridades periféricas teriam importante papel na origem da formação dessa estrutura produtiva, no período pós-1930, quando o expediente de obtenção da casa própria passou a exercer um papel decisivo na redução do custo da reprodução da força de trabalho, indispensável para a nova hegemonia que se construía.

Entre 1970 e 1990, nessa chave interpretativa, desenvolveram-se as relações entre capital industrial periférico e dependente, concentrado na região sudeste do Brasil - e produção do espaço urbano, pela qual se desenhariam múltiplas dimensões morfológicas do urbano, em especial as relações entre classes sociais e cidade, além das relações entre localizações e formas de concentração industrial e conformação urbana. De modo transversal, buscou-se explicar as desigualdades presentes no território a partir das formas e estratégias de segregação socioespacial, inscritas em um modelo que lia o centro em oposição às periferias. Nesse contexto, construiu-se uma representação da cidade periférica, através de uma série de estudos sobre os loteamentos populares e autoconstrução (Bonduki e Rolnik, 1979; Maricato, 1979), em um esforço de compreensão sobre as formas de moradia na metrópole que se desenhava, pelo qual também se iluminaram os cortiços presentes em áreas centrais mais dinamizadas e infraestruturadas (Kohara, 1999; Kowarick e Ant, 1982; Piccini, 1999).

Também comporia esta trama conceitual as questões que dizem respeito ao Estado e às formas de intervir na cidade, embaralhadas a uma aparente desordem (Brant e Kowarick, 1975), iluminando-se planos e estratégias de regulação urbanística que atentaram para os desdobramentos de um Brasil que se constituía predominantemente urbano (Santos, 1980; Feldman, 2005; Villaça, 1999). Constituiu-se, ainda, importante campo de discussão e de elaboração teórica sobre a classe trabalhadora e as classes populares que conformaram o quadro de constituição de movimentos sociais como sujeitos políticos de grande potencial na transformação da cidade, organizados em torno das demandas urbanas (Sader, 1988).

A partir dos anos 2000, uma visão diversificada e multifacetada dos territórios periféricos foi evidenciada (Ribeiro, 2000; Marques, 2015), afirmando a impossibilidade de tematizar a "periferia" como se fosse homogênea, em oposição dual ao "centro", ainda que suas diferenças estruturais estivessem mantidas. Neste sentido, é possível afirmar que esta heterogeneidade dos territórios populares foi resultado de várias décadas de investimentos públicos (Pasternak e D’Ottaviano, 2016) em intervenções e melhorias urbanísticas através de obras de saneamento, transporte, equipamentos e serviços sociais nos bairros periféricos e em suas conexões com as centralidades urbanas, em processos altamente mediados pela competição político-eleitoral. 




\section{SÃO PAULO15 17 LISBOA $25 \sim 26$ JUN 2020

\section{MCMV Entidades e o novo quadro de políticas habitacionais no Brasil}

Na esteira dessas novas interações, destaca-se o programa MCMV4 como política anticíclica de emprego, de estratégia bem-sucedida e de perfil distributivista, através do qual o Governo Federal pretendia direcionar, pela concentração de recursos e mecanismos de proteção ao financiamento, o deslocamento de atuação do mercado imobiliário para as faixas de renda mais baixas. Do ponto de vista territorial, o programa parece ter se atribuído uma "marca" caracterizada pelos mesmos aspectos produtivos, construtivos e de inserção urbana, que constituem a habitação social de mercado (Shimbo, 2012), relacionando a localização dos empreendimentos, a padronização dos projetos e a escala ampliada dos produtos arquitetônicos e urbanos resultantes dessa produção, à alta lucratividade obtida pelas grandes construtoras e incorporadoras atuantes no programa e mobilizadoras da maior parte de seus recursos financeiros.

Foi parte dessa engrenagem a modalidade "Entidades" (MCMV Entidades) 5 que apresentou-se bastante emblemática, pois através de sua análise será possível flagrar vínculos complexos, com consequências nada desprezíveis para o rearranjo do campo de forças entre movimentos de moradia e reforma urbana, o Estado e o mercado imobiliário, na operação de um novo diagrama de relações entre produção de moradia e luta pela apropriação da cidade (ou seu avesso) (Rizek, Santo Amore e Camargo, 2014 e 2015; Camargo, 2016).

Apesar de se tratar de uma produção ínfima em termos quantitativos ${ }^{6}$, se comparada a toda produção do MCMV, a presença da modalidade Entidades teve uma dimensão política paradigmática, apoiando-se na tradição de políticas habitacionais autogestionárias, envolvendo os mais representativos movimentos de luta por moradia e reforma urbana do Brasil. Inscreve-se, por este ângulo, em um percurso histórico em torno de um programa federal que disponibilizasse recursos e fosse estruturado a partir da autogestão, com um conjunto de questões formuladas em dois momentos de debates que envolveram sua prática: o primeiro, nas décadas 1970/80, onde se combinaram novas formas de representação da cidade periférica e a emergência dos movimentos sociais que se consolidavam a partir das influências de uma vertente libertária da igreja católica e de um conjunto de experiências em curso em outros países da América Latina, que envolviam práticas de mutirão vinculadas à produção de moradia; o segundo, de avaliação das experiências emblemáticas de produção habitacional através de procedimentos autogestionários desenvolvidas, sobretudo, entre as décadas 1980/90, em São Paulo (Camargo, 2016).

Do ponto de vista de sua distribuição no território, a produção do MCMV Entidades aparece ancorada às porções do território inseridas em dinâmicas metropolitanas onde a mobilização social já apresenta alguma trajetória anterior e onde se concentra a demanda por moradias dignas. Por outro lado, na escala metropolitana, essa produção apresentará dinâmicas distintas, concentrando-se, na RMSP, em sua

\footnotetext{
${ }^{4}$ A primeira fase do programa foi instituída pela Medida Provisória № 459, de 25 de março de 2009, posteriormente convertida na Lei no 11.977 , de 7 de julho de 2009 , e demais normas infra legais. A segunda fase foi regulamentada pela Lei no 12.424 , de 16 de junho de 2011. Já a terceira fase do programa foi regulamentada pela Lei oㅡ 698, de 30 de março de 2015 e sofreu uma série de alterações através de Medidas Provisórias subsequentes, até o momento presente, que anuncia modificações mais profundas no programa.

${ }^{5}$ Integraram o MCMV, além da "Construtoras", as modalidades Entidades, PNHR (rural) e Sub 50 (municípios com menos de 50 mil habitantes), incluídos sob intensas reivindicações e representando menos de $10 \%$ das metas físicas e financeiras em seu lançamento, em 2009 .

${ }^{6}$ De acordo com dados obtidos no Ministério das Cidades (e-SIC) em setembro de 2018, entre julho de 2009 e julho de 2018 , o programa contratou 5.357 .940 milhões de unidades habitacionais para diferentes faixas de renda. Desse total, $34,63 \%$ foram contratações para a faixa de atendimento 1 e somente $1,46 \%$ (aproximadamente 76 mil) das unidades contratadas foram destinadas a modalidade Entidades. No que se refere aos recursos contratados, apenas $0,51 \%$ do total do programa foi destinado à modalidade Entidades.
} 


\section{XII}

ocupação, aluguel popular, autoconstrução), entrecruzado a dispositivos operacionais de programas habitacionais distintos.

Nesta chave, destacam-se as ações relacionadas à moradia popular envolvendo o governo estadual e municipal de São Paulo, por meio de programas que se desenham e se relacionam ao atendimento provisório e permanente habitacional, como alternativa aos cortes financeiros e coordenadas alterações de determinadas normativas operacionais, que prejudicam a conclusão de obras contratadas pelo MCMV - para as famílias de menores rendimentos e à suspensão de novas contratações, bem como pelas desarticuladas e inacabadas propostas do governo federal no âmbito do desenho de um novo programa de atendimento habitacional.

\section{Considerações Finais}

De um modo geral, talvez seja possível apontar para a natureza das práticas que envolvem a implementação deste programa como síntese de longos processos: a "confluência perversa" (Dagnino, 2001) que imputou novas formas de relações entre Estado e sociedade brasileira no contexto de democratização, mediada por entidades difusas; o uso de recursos oriundos de fundos públicos financiando novas formas de intervenção do Estado e do capital no espaço urbano; as práticas que envolvem a produção de moradias imbricadas a práticas de mercado que reduzem seu valor de uso e incitam a construção de mercadorias políticas; projetos arquitetônicos e urbanísticos, em geral padronizados e rebaixados ao nível das carências já vivenciadas, produzindo os novos locais de moradia; a fragmentação dos territórios urbanos periféricos, a partir das piores áreas ainda disponíveis, reforçadas de um lado, pelo porte, contiguidade ou proximidade, e pelas formas arquitetônicas carimbadas e "resolvidas" em condomínios fechados, e de outro, pelas friç̧ões imputadas pelos processos, tal como se desenham nestes espaços (Camargo, 2020).

Já da perspectiva da análise sobre as práticas e a agenda dos movimentos de moradia parece importante destacar o lugar assumido pelos mesmos no contexto político recente, primeiro, na reivindicação de manutenção do programa, fortemente ameaçado, que dão conta da organização de determinado campo pela aglutinação de formas múltiplas associativas e de movimentos sociais distintos, bem como por parte da Academia e Assessorias Técnicas, frente às novas e mais restritivas condições de operacionalidade e cortes financeiros significativos e, de modo mais amplo, na retomada de uma agenda pública em torno da reforma urbana; e segundo, em novas articulações que se desenham (re)envolvendo as esferas federativas locais e estaduais, e a prospecção de novos programas habitacionais onde, certamente, esse "lugar" seguirá sendo disputado.

Em outra escala de interações, destaca-se a produção habitacional resultante das articulações de movimentos de moradia organizados em redes latino-americanas. Essas redes atuam, sobretudo, na identificação, documentação e difusão de uma determinada produção habitacional que, em tese, sustenta-se em práticas autogestionárias, através de um sem número de apoios financeiros para construção de estratégias de incidência. Por este recorte, seria possível entrever um campo tecido pela circulação de proposições e práticas implementadas por agências multilaterais e organizações internacionais, em um quadro de novas formulações em torno do tema da governança, que dão conta do continente latinoamericano e de suas populações mais empobrecidas como laboratório de políticas públicas (Maranhão, 2018). Por essa lente, parece relevante analisar a circulação de ideias no âmbito mais amplo de formulação das políticas públicas habitacionais latino-americanas que tanto impulsionaram a produção da "habitação 



\section{SÃO PAULO15 17 LISBOA $25 \sim 26$ JUN 2020

BRANT e KOWARICK. (1975). A lógica da desordem. In: CAMARGO, Cândido et al. São Paulo, 1975: crescimento e pobreza. São Paulo: Edições Loyola.

BRENNER, N. (2013). Reestruturação, reescalonamento e a questão urbana. São Paulo: GEOUSP - espaço e tempo, n.33, 198-220.

BONDUKI, N. e ROLNIK, R. (1979). Periferias: ocupação do espaço e reprodução da força de trabalho. São Paulo: Prodeurb/FAU-USP.

CAMARGO, C. (2016). Minha Casa Minha Vida Entidades: entre os direitos, as urgências e os negócios. São Carlos: Instituto de Arquitetura e Urbanismo USP (Tese de Doutorado).

CAMARGO, C. (2020) MCMV Entidades: novos arranjos para a operação da política habitacional no Brasil. Artigo aceito para publicação. Revista Brasileira de Ciências Sociais (no prelo).

DAGNINO, E. (2001). Construção democrática, neoliberalismo e participação: os dilemas da confluência perversa. In: Política e Sociedade, n. 5, p. 139-164.

FELDMAN, S. (2005). Planejamento e Zoneamento em São Paulo - 1947-1972. São Paulo: Edusp.

FERREIRA, J.S.W. (2007). O mito da cidade-global: o papel da ideologia na produção do espaço urbano. São Paulo/Petrópolis/Salvador : Ed. UNESP/VozesS/ANPUR.

FIX, M. (2007). São Paulo, cidade global: fundamentos financeiros de uma miragem. São Paulo : Boitempo.

HARVEY, D. (2014). Cidades Rebeldes. São Paulo: Martins Fontes.

KOHARA, L. (1999). Rendimentos obtidos na locação e sublocação de cortiços: estudos de casos na área central da cidade de São Paulo. São Paulo: FAU USP (Dissertação de Mestrado).

KOWARICK, L. e ANT, C. (1982). O cortiço: cem anos de promiscuidade. Novos Estudos, n.2, 59-70.

KLINK, J. (2013). A escalaridade e a espacialidade do (novo) desenvolvimento: uma exploração conceitual para o debate. In: BRANDÃO, C.; SIQUEIRA, H. Pacto federativo, integração nacional e desenvolvimento regional. São Paulo: Editora Fundação Perseu Abramo.

KLINK, J. e BARCELLOS DE SOUZA, M. (2017). Financeirização: conceitos, experiências e a relevância para o campo do planejamento urbano brasileiro. In Cadernos Metrópole, v. 19, 379-406.

LAVAL, Christian e Dardot, Pierre. (2016). A nova razão do mundo: ensaio sobre a sociedade neoliberal. São Paulo : Boitempo.

MARANHÃO, T. (2018). O Consenso das Oportunidades: Banco Mundial e PNUD no combate à pobreza. São Paulo: Alameda Editorial.

MARQUES, E. (2015) Condições habitacionais e urbanas no Brasil. In ARRETCHE, M. (org.). A metrópole de São Paulo no século XXl: espaços, heterogeneidades e desigualdades (337-365). São Paulo: Ed. Unesp/CEM.

MARICATO, E. (1979). A produção capitalista da casa e da cidade no Brasil Industrial. São Paulo: Alfaômega. 


\section{SÃO PAULO15 17 LISBOA $25 \sim 26$ JUN 2020

NAKANO, A. K. (2019). Estimativa da População em Insegurança Habitacional potencial Residente na Região Metropolitana de São Paulo. In Anais XVIII ENANPUR, Natal.

OLIVEIRA, F. (1972). A economia brasileira: crítica à razão dualista. In: Seleção CEBRAP, n.2. São Paulo: Brasiliense.

PASTERNAK, S. e D`OTTAVIANO, C. (2016). Favelas no Brasil e em São Paulo: avanços nas análises a partir da leitura territorial do Censo de 2010. In Cadernos da Metrópole, v.18, n.35, 75-100.

PAULANI, L. (2008). Brasil delivery. São Paulo: Boitempo

PICCINI, A. (1999). Cortiços na cidade: Conceitos e Preconceitos na reestruturação do centro urbano de São Paulo. São Paulo: Annablume.

RIBEIRO, L.C. de (2000). O futuro das metrópoles: desigualdade e governabilidade. Rio de Janeiro: REVAN/FASE.

RIZEK, C. (2015). Gestão da Cidade/Gestão Diferencial da Vida/Confinamento e Moralização. In JACQUES, Paola B. e BRITTO, Fabiana D. (orgs.) Experiências metodológicas para compreensão da complexidade da cidade contemporânea (28-51). Salvador: EDUFBA.

RIZEK, C; SANTO AMORE, C; CAMARGO, C. (2015). Política Habitacional e Políticas Sociais: urgências, direitos e negócios. In CARLOS, Ana Fani; VOLOCHKO, Danilo e ALVAREZ, Isabel P (orgs.). A cidade como negócio (165-184). São Paulo: Contexto.

ROLNIK, R. (2015). Guerra dos Lugares. São Paulo: Boitempo Editorial.

ROLNIK, R. e SANTORO, P. (2017). Novas frentes de expansão do complexo imobiliário-financeiro em São Paulo. In: Cadernos Metrópole (PUCSP), v.19, 407-431.

ROYER (2014). Financeirização da Política Habitacional: limites e perspectivas. São Paulo, Annablume.

RUFINO, SHIMBO e SANTO AMORE (org.) (2015). Minha Casa... E a cidade? Avaliação do programa Minha Casa Minha Vida em seis estados brasileiros. Rio de Janeiro: Letra Capital.

SADER, E. (1988). Quando novos personagens entram em cena: experiências, falas e lutas dos trabalhadores da Grande São Paulo (1970-1980). São Paulo: Paz e Terra.

SANFELICI, D. (2013). A metrópole sob o ritmo das finanças: implicações socioespaciais da expansão imobiliária no Brasil. São Paulo, FFLCH USP (Tese de Doutorado).

SANFELICI, D. (2015). As escalas de acumulação na produção das cidades. In CARLOS, VOLOCHKO e ALVAREZ (orgs.). A Cidade como negócio (121-146). São Paulo: Contexto.

SANTOS, M. (1980). A urbanização desigual. Petrópolis: Vozes.

SHIMBO, L. (2012). Habitação social de mercado: a confluência entre Estado, empresas construtoras e capital financeiro. São Paulo: c/ARTE.

TATAGIBA, L. (2002). Os Conselhos Gestores e a democratização das políticas públicas no Brasil. In DAGNINO, E. (org.). Sociedade Civil e Espaços Públicos no Brasil. São Paulo: Paz e Terra. 


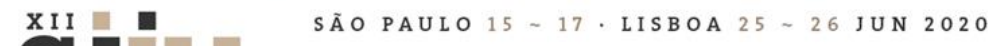

TELLES, V. (2013). Prospectando a cidade a partir de suas margens: notas inconclusas sobre uma experiência etnográfica. In: Contemporânea. Dossiê Fronteiras Urbanas, v.3, n.2, p. 359-373.

TORRES, H. da G. e MARQUES, E. (2001). Reflexões sobre a hiperperiferia: novas e velhas faces da pobreza no entorno municipal. In: Revista Brasileira de Estudos Regionais e Urbanos, n 4, 49-70.

VILLAÇA, F. (1999). Uma contribuição para a história do planejamento urbano no Brasil. In DEÁK, C. e SCHIFFER, S. (org.) O processo de urbanização no Brasil (169-243). São Paulo: EdUSP. 